\title{
Bioactive self-assembled peptide nanofibers for corneal stroma regeneration
}

\author{
G. Uzunalli a , Z. Soran ${ }^{a}$, T.S. Erkal ${ }^{a}$, Y.S. Dagdas ${ }^{a}$, E. Dinc ${ }^{b}$, A.M. Hondur ${ }^{c}$, K. Bilgihan ${ }^{c}$, B. Aydin ${ }^{c, *}$, \\ M.O. Guler ${ }^{\mathrm{a}, *}$, A.B. Tekinay ${ }^{\mathrm{a}, *}$ \\ a Institute of Materials Science and Nanotechnology, National Nanotechnology Research Center (UNAM), Bilkent University, Ankara 06800, Turkey \\ ${ }^{\mathrm{b}}$ Department of Ophthalmology, School of Medicine, Mersin University, Mersin, Turkey \\ ${ }^{\mathrm{c}}$ Department of Ophthalmology, Gazi University, Ankara, Turkey
}

\section{A R T I C L E I N F O}

\section{Article history:}

Received 22 July 2013

Received in revised form 29 November 2013

Accepted 5 December 2013

Available online 12 December 2013

\section{Keywords:}

Corneal stroma regeneration

YIGSR

RGD

Peptide amphiphile

Self-assembly

\begin{abstract}
A B S T R A C T
Defects in the corneal stroma caused by trauma or diseases such as macular corneal dystrophy and keratoconus can be detrimental for vision. Development of therapeutic methods to enhance corneal regeneration is essential for treatment of these defects. This paper describes a bioactive peptide nanofiber scaffold system for corneal tissue regeneration. These nanofibers are formed by self-assembling peptide amphiphile molecules containing laminin and fibronectin inspired sequences. Human corneal keratocyte cells cultured on laminin-mimetic peptide nanofibers retained their characteristic morphology, and their proliferation was enhanced compared with cells cultured on fibronectin-mimetic nanofibers. When these nanofibers were used for damaged rabbit corneas, laminin-mimetic peptide nanofibers increased keratocyte migration and supported stroma regeneration. These results suggest that laminin-mimetic peptide nanofibers provide a promising injectable, synthetic scaffold system for cornea stroma regeneration.
\end{abstract}

( 2013 Acta Materialia Inc. Published by Elsevier Ltd. All rights reserved.

\section{Introduction}

The cornea acts as a barrier to protect the eye from external effects and has a major role in the refractive nature of the eye [1]. It is a dome-shaped, transparent, avascular and immune privileged tissue, which contains three major layers: the outermost epithelium layer; the stroma; and the innermost endothelium layer [1-3]. The structure and thickness of these layers are crucial for the cornea's transparency. Corneal opacification due to inflammation, trauma or corneal dystrophies such as keratoconus or keratoglobus results in vision loss affecting ten million people worldwide annually, who are generally treated by cornea transplantation [4,5]. Even though the need for cornea donation increases each year, the number of suitable donors decreases owing to widespread use of laser vision corrective surgery, which makes the cornea unusable for transplantation.

The stroma is the thickest part of the cornea. It is formed by quiescent corneal fibroblasts, keratocytes, which are sandwiched between collagen lamellae [6]. Uniform spacing between collagen fibers and their parallel organization are thought to have roles in corneal transparency and enhanced light transmission. Damage

\footnotetext{
* Corresponding authors.

E-mail addresses: baydunus@yahoo.com (B. Aydin), moguler@unam.bilkent. edu.tr (M.O. Guler), atekinay@bilkent.edu.tr (A.B. Tekinay).
}

to the ultrastructural organization of the corneal stroma can lead to irreversible loss of transparency. Stroma thinning, which is observed in keratoconus, also prevents the cornea from proper functioning. To address problems associated with corneal stroma, many different corneal substitutes, such as keratoprosthesis [7] or tissue engineered corneal equivalents [8], have been constructed. Keratoprosthesis has been employed for more than a century, but the most promising commercial keratoprostheses $[9,10]$ were reported to cause progressive stroma melting and epithelial defects [11]. Various biomaterials have been suggested for use in tissue engineered corneal equivalents, including collagen [12,13], fibrin-agarose [14] and decellularized cornea [15]. Because of its high optical clarity, it is important to design a scaffold that preserves the transparency of the cornea. Moreover, this scaffold should possess high biocompatibility ad non-immunogenicity [16].

Peptide amphiphile (PA) molecules self-assemble into nanofibers through intermolecular forces [17]. The self-assembly mechanism is based on hydrophobic interactions of alkyl tails, intermolecular hydrogen bonding and electrostatic interactions between the charged groups. At physiological pH, electrostatic interactions between oppositely charged molecules promote selfassembly without any external trigger [18]. Therefore, oppositely charged peptides molecules are mixed to form nanofibers at the physiological $\mathrm{pH}$. The interactions between these nanofibers make up a three-dimensional (3-D) network, which encapsulates water and results in a hydrogel structure. Since the peptide segment of 
the PA molecules can be designed to provide biological signals, PA nanofiber networks are promising biomaterials for achieving controlled cell-material interactions. Because of their versatile physical, chemical and biological features, they have been used as synthetic extracellular matrix (ECM) mimicking agents for cartilage [19], bone [20] and neural regeneration [21] and angiogenesis [22]. Various sets of peptide epitopes, which are found in ECM proteins such as laminin, collagen and fibronectin, are known to play crucial roles in the maintenance of cell survival and function. For example, the YIGSR sequence derived from laminin $\beta$-chain regulates cell adhesion through binding to laminin binding protein [23-25]. As an alternative to YIGSR, the RGD sequence derived from fibronectin can also be used for attachment of the cells to the ECM. Previously, RGD-containing peptides were observed to act as cell adhesive agents when they were immobilized on the surface [26]. These characteristic sequences regulate biological activities through activating and/or inhibiting protein targets with high specificity [27]. Owing to the short lengths of these peptide sequences, they are more stable and easier to manipulate, and show fewer conformational changes compared with whole proteins [28]. Therefore, it is convenient to use such sequences in pharmaceutical and clinical applications.

Versatile functional groups, the easy implementation capability and the self-assembly property of PA networks make them promising biomaterials for corneal tissue engineering. In this study, PA molecules carrying bioactive peptide sequences, YIGSR and RGD derived from laminin and fibronectin, were used to induce corneal regeneration. Healing of corneal wounds depends on the balance between cellular proliferation, differentiation, apoptosis and motility in the damaged area. Materials that can regulate these behaviors simultaneously can mimic the native environment of cells and play vital roles in the maintenance of normal corneal function [29].

\section{Materials and methods}

\subsection{Materials}

The 9-fluorenylmethoxycarbonyl (Fmoc) and other protected amino acids, lauric acid, [4-[ $\alpha$ - $\left(2^{\prime}, 4^{\prime}\right.$-dimethoxyphenyl $)$ Fmoc-amino methyl] phenoxy] acetomidonorleucyl-MBHA resin (Rink amide MBHA resin), 2-(1H-Benzotriazol-1-yl)-1,1,3,3-tetramethyluronium hexafluorophosphate (HBTU) and diisopropylethylamine were purchased from Merck and ABCR. The 100-200 mesh Wang resin was purchased from NovaBiochem, and valine was loaded on it for producing Fmoc-Val-Wang resin. All other chemicals and materials used in this study were analytical grade and obtained from Invitrogen, Fisher, Merck, Alfa Aesar and Sigma-Aldrich.

\subsection{Synthesis and purification of PA molecules}

The YIGSR-PA (Lauryl-VVAGKYIGSR-Am), KKRGD-PA (LaurylVVAGKKRGD-Am), K-PA (Lauryl-VVAGK-Am) and E-PA (LaurylVVAGE-OH) molecules were synthesized using Fmoc solid phase peptide synthesis. Synthesis was performed manually on a $1 \mathrm{mmole}$ scale using a $50 \mathrm{ml}$ peptide synthesis vessel on a wrist action shaker. Either Fmoc-Glu-(OtBu)-Wang resin or Rink amide resin was used for synthesis. Before each coupling reaction, Fmoc groups were removed by shaking resin in $20 \%$ piperidine in $\mathrm{N}, \mathrm{N}$-dimethylformamide (DMF) for $20 \mathrm{~min}$. After each reaction, the resin was washed three times with DMF, dichloromethane (DCM) and DMF, respectively. All amino acids were activated by adding 2 molar equivalents of amino acid to 1.95 equivalents of O-Benzotriazole-N,N, $\mathrm{N}^{\prime}, \mathrm{N}^{\prime}$-tetramethyl-uronium-hexafluoro-phosphate (HBTU) and dissolved in $10 \mathrm{ml}$ of DMF. After complete dissolution of amino acid and HBTU in DMF, 3 molar equivalents of $N$-ethyl-diisopropylamine were added to the solution. The solution was mixed thoroughly and kept for $3 \mathrm{~min}$ before adding to the resin. Each coupling reaction was performed for $2 \mathrm{~h}$. Peptide alkylation reaction was performed by coupling lauric acid to the peptide. A ninhydrin test was performed after addition of each amino acid and after addition of the lauric acid. When the ninhydrin test yielded positive results, coupling reaction was repeated; otherwise $10 \mathrm{ml}$ of $10 \%$ acetic anhydride/DMF solution was added, and the resin was sha ken for $30 \mathrm{~min}$. Peptide cleavage and deprotection were performed with 95:2.5:2.5 trifluoroacetic acid (TFA):triisopropylsilane:water for $2 \mathrm{~h}$ at room temperature (RT). After the cleavage reaction, PA molecules were collected in a clean round-bottom flask, and the DCM wash was performed several times. Collected solution was rotary evaporated. After evaporation, ice-cold diethyl ether was added, and sample was left at $-20^{\circ} \mathrm{C}$ overnight. The PA-diethyl ether mixture was collected in $50 \mathrm{ml}$ falcon tubes and centrifuged at $6000 \mathrm{rpm}$ for $20 \mathrm{~min}$. The supernatant was decanted, and the remaining diethyl ether was evaporated. The pellet was dissolved in deionized water at a resistance of $18.2 \Omega$ and was freeze-dried. Characterization of synthesized PA was done using Agilent 6530 quadrupole time-of-flight mass spectrometry with an electrospray ionization source equipped with reverse-phase analytical high-performance liquid chromatography (HPLC) with an Agilent Zorbax Extend-C18 $2.1 \times 50 \mathrm{~mm}$ column for basic conditions or a Zorbax SB-C8 $4.6 \times 100 \mathrm{~mm}$ column for acidic conditions (Figs. S1-6). A gradient of $0.1 \%$ formic acid/ water for acidic conditions or $0.1 \%$ ammonium hydroxide/acetonitrile for basic conditions was used as mobile phase for analytical HPLC. An Agilent preparative reverse-phase HPLC system equipped with a Zorbax Extend-C18 $21.2 \times 150 \mathrm{~mm}$ column for basic conditions and a Zorbax SB-C8 $21.2 \times 150 \mathrm{~mm}$ column for acidic conditions were used for the purification of PA molecules. The residual TFA in PA samples was removed by $\mathrm{HCl}$ treatment by dissolving in $0.01 \mathrm{M} \mathrm{HCl}$ solution and freeze drying. An Agilent preparative reverse-phase HPLC system equipped with Zorbax Extend-C18 $21.2 \times 150 \mathrm{~mm}$ column was used for purifying E-PA molecule.

\subsection{Physical and chemical characterization of PA molecules}

In the physical and chemical characterizations of peptide nanofiber systems used for in vitro studies, negatively charged E-PA was used as a non-bioactive gelator molecule for mixing with positively charged YIGSR-PA, KKRGD-PA and K-PA. Nanofibers were formed through self-assembly of the PA molecules caused by electrostatic interactions. Since positively charged PA solutions formed gel in the corneal pocket following injection, owing to the presence of negatively charged molecules such as chondroitin sulfate (CS) and keratin sulfate in native cornea, CS was used to induce nanofiber formation with positively charged YIGSR-PA and KKRGD-PA molecules for characterizing the peptide nanofiber systems used for in vivo studies. In these experiments, the PA molecules were dissolved in $0.25 \mathrm{M}$ sucrose solution, unless specified otherwise, since injections into the cornea were also performed in a similar manner.

\subsubsection{Atomic force microscopy}

PA solutions were prepared by mixing 0.05 wt.\% YIGSR-PA, KKRGD-PA or K-PA with E-PA at a 2:1 volume ratio, or $0.05 \mathrm{wt} . \%$ YIGSR-PA and KKRGD-PA with $0.1 \%$ CS at a $7: 1$ volume ratio. Because sucrose solution prevented cantilever mobility, all PA molecules were dissolved in water. Then, $10 \mu \mathrm{l}$ of the final solutions were drop-cast on silicon wafers and air dried. Atomic force microscopy (AFM) images were taken by MFP-30 Asylum Research in tapping mode, using a cantilever with stiffness $k=40 \mathrm{~N} \mathrm{~m}^{-1}$ and resonance frequency $f=250-350 \mathrm{kHz}$. 


\subsubsection{Transmission electron microscopy}

Transmission electron microscopy (TEM) samples were prepared on a Lacey carbon-coated 300-mesh copper grid, and $10 \mu \mathrm{l}$ of the solutions were dropped on a grid and incubated for $3 \mathrm{~min}$ before staining. The excess amount was removed by tissue paper, and 2 wt.\% uranyl acetate solution was used for staining the organic nanostructures. The samples were imaged by FEI Tecnai G2 F30.

\subsubsection{Circular dichroism}

Circular dichroism (CD) spectra of the PA solutions were obtained on a J-815 Jasco CD spectrophotometer in the far UV region using quartz cuvettes with a $1 \mathrm{~mm}$ path length. The $C D$ spectra of YIGSR-PA/E-PA, KKRGD-PA/E-PA, K-PA/E-PA, YIGSR-PA/CS and KKRGD-PA/CS were acquired. For preparation of YIGSR-PA/E-PA, KKRGD-PA/E-PA and K-PA/E-PA samples, PA molecules were dissolved in deionized water at a concentration of $0.01 \mathrm{wt} . \%$ and mixed in a 2:1 ratio. For preparation of YIGSR-PA/CS and KKRGD$\mathrm{PA} / \mathrm{CS}$ samples, PA molecules were dissolved in $0.25 \mathrm{M}$ sucrose solution at a concentration of $0.01 \mathrm{wt} . \%$, CS was dissolved in deionized water at a concentration of $0.02 \mathrm{wt} . \%$, and they were mixed in a ratio of $7: 1$. The $\mathrm{pH}$ value of each solution was adjusted to 7.4 with $1 \mathrm{M} \mathrm{NaOH}$ before characterization. An average of three scans of each sample was used. CD spectra were obtained from $190 \mathrm{~nm}$ to $300 \mathrm{~nm}$, using a digital integration time of $1 \mathrm{~s}$, a band width of $1 \mathrm{~nm}$ and a data pitch of $0.1 \mathrm{~nm}$.

\subsubsection{Scanning electron microscopy}

The nanofiber network formation of PA molecules was investigated by scanning electron microscopy (SEM) imaging performed with a FEI Quanta 200 FEG under high vacuum. For preparation of YIGSR-PA/E-PA, KKRGD-PA/E-PA and K-PA/E-PA samples, $1 \mathrm{wt}$.\% PA solutions were mixed at a ratio of $2: 1$. For YIGSR-PA/CS and KKRGD-PA/CS samples, PA solutions and CS solution were mixed at a volume ratio of 9:1. Gels were incubated for $20 \mathrm{~min}$ for maturation, and dehydrated gradually with increasing concentrations of ethanol. Samples were dried in a critical-point dryer (Tousimis, Autosamdri-815B) and coated with $6 \mathrm{~nm}$ of $\mathrm{Au} / \mathrm{Pd}$.

\subsection{Cell culture and maintenance}

The viability, spreading and proliferation profiles of cells on PA molecules were studied using the telomerase immortalized human corneal keratocyte (HTK) cell line previously developed by Jester et al. [30]. HTK were cultured in $75 \mathrm{~cm}^{2}$ polystyrene cell culture flasks with Dulbecco's Modified Eagle Medium containing 10\% fetal bovine serum and $1 \%$ penicillin/streptomycin [30]. In vitro experiments and passaging of cells were performed when cultures became $\sim 80 \%$ confluent.

\subsubsection{Analysis of in vitro effects of PA molecules}

Three experimental groups were designed to assess the biocompatibility and bioactivity of PA molecules on HTK cells. While K-PA/ E-PA was used as nanofiber control, YIGSR-PA/E-PA and KKRGDPA/E-PA were used as bioactive nanofiber networks. Collagen was used as positive control. For in vitro experiments, all positively charged PA were mixed with negatively charged E-PA. For each experiment, 0.2 wt.\% YIGSR-PA/E-PA, KKRGD-PA/E-PA and K-PA/ E-PA were mixed at $1.85: 1,1.7: 1$ and $2: 1$ volume ratios, respectively, and $0.01 \mathrm{wt} \%$ collagen solution was used for collagentreated samples. Experiments were performed in 96-well plates containing $100 \mu \mathrm{l}$ of total PA solution or $40 \mu \mathrm{l}$ of collagen solution. Coated plates were incubated at $37^{\circ} \mathrm{C}$ for $30 \mathrm{~min}$, and solvents were evaporated in a laminar flow hood overnight. Before culturing HTK, plates were UV-sterilized for at least $15 \mathrm{~min}$, then $3 \times 10^{3}$ HTK were seeded into each well.
To determine the viability and proliferation of HTK quantitatively, an Alamar blue assay was performed: $3 \times 10^{3}$ cells were seeded in 96-well plates and cultured for viability and proliferation for $24 \mathrm{~h}$ and $72 \mathrm{~h}$, respectively. The Alamar blue assay was performed according to manufacturer's instructions and fluorescence spectrum was measured at an excitation of $540-570 \mathrm{~nm}$ and emission of $580-610 \mathrm{~nm}$.

\subsubsection{Spreading}

Spreading of HTK was investigated by staining filamentous actins and nuclei with TRITC-conjugated phalloidin and TO-PRO ${ }^{\circledR}-3$ iodide, respectively. In order to evaluate vimentin expression, which is a keratocyte marker, cells were stained with anti-vimentin antibody, and $15-\mathrm{mm}$ glass cover slips were coated with PA molecules or collagen as described above. Coated cover slips were placed in 24-well plates, $2 \times 10^{4} \mathrm{HTK}$ were seeded in each well, and were incubated for $24 \mathrm{~h}$ at $37^{\circ} \mathrm{C}$ with $5 \% \mathrm{CO}_{2}$. Cells were fixed by treating with $4 \%$ paraformaldehyde for $15 \mathrm{~min}$ and were washed three times with PBS. After permeabilization had been performed via $0.1 \%$ Triton $\mathrm{X}-100$ treatment in PBS with $1 \%$ bovine serum albumin (BSA), samples were incubated in blocking solution for $2 \mathrm{~h}$. At the end of the incubation time, samples were incubated with anti-vimentin antibody (1:200) overnight at $4{ }^{\circ} \mathrm{C}$. Alexafluor-488 conjugated secondary antibody was used at 1:500 dilution. Following the PBS wash, samples were stained with FITC-phalloidin $(1: 500)$ and TO-PRO ${ }^{\circledR}-3$ iodide $(1: 1000)$ for 20 min each at RT. Samples were mounted with ProLong anti-fade mounting media and were imaged with Zeiss LSM 510 confocal microscope.

Cell-nanofiber interaction was also assessed by electron microscopy. HTK cultured on PA-coated, collagen-coated and bare glass surfaces were incubated for $24 \mathrm{~h}$. Fixation with $2.5 \%$ gluteraldehyde was followed by $1 \mathrm{wt} . \% \mathrm{OsO}_{4}$ treatment. Subsequently, water content was removed by gradual increase of ethanol. Samples within $100 \%$ ethanol were dried with a Tourismis Autosamdri ${ }^{\circledR}-815 B$ critical-point dryer. Dried samples were coated with $4 \mathrm{~nm} \mathrm{Au/Pd}$ and imaged under high vacuum mode SEM with a FEI Quanta 200 FEG instrument equipped with an ETD detector.

\subsection{In vivo experiments}

In vivo experiments were carried out with 15 young adult New Zealand white rabbits weighing between 2.5 and $3.0 \mathrm{~kg}$. Rabbits were maintained on ad libitum access to water and nutrition in a 12 h-12 h light-dark cycle. All animal studies were approved by Mersin University Animal Studies Ethical Committee, and all experiments were conducted in accordance with the Animal Care and Use Committee and the ARVO statement for the Use of Animals in Ophthalmic and Vision Research.

\subsubsection{Surgical procedure}

YIGSR-PA and KKRGD-PA molecules were dissolved in $0.25 \mathrm{M}$ sucrose solution and sterilized under UV for $2 \mathrm{~h}$. Rabbits were anesthetized with an intramuscular injection of $50 \mathrm{mg} \mathrm{kg}^{-1}$ ketamine hydrochloride and $5 \mathrm{mg} \mathrm{kg}^{-1}$ xylazine hydrochloride. Under general anesthesia, corneal stromal pockets $7-8 \mathrm{~mm}$ in diameter were made by lamellar dissection of the cornea with a fine corneal spatula, and 1 wt.\% PA solutions were injected into corneal stromal pocket. After injection, the entrance of the corneal stromal pocket was sutured. In the negative control group, a corneal stromal pocket was formed in a similar fashion, and the entrance was sutured without any injection and is referred to as "corneal pocket without injection". At the end of surgery, subconjunctival injection of $0.1 \mathrm{ml}$ dexamethasone/netilmicin was carried out. Topical dexamethasone/netilmicin $(0.1 \% / 0.3 \%)$ eye drops were administered four times a day for 1 week after the procedure. During the study, all the eyes were examined clinically for corneal clarity and for any 
sign of inflammation or infection. YIGSR-PA $(n=4 ; n=4)$ and KKRGD-PA ( $n=3 ; n=4)$ injected corneas were surgically removed after 3 or 7 weeks, for histological and immunohistochemical (IHC) characterization. Also, corneal pocket without injection $(n=3$; $n=2)$ and native $(n=2 ; n=2)$ corneas were used as negative and positive control groups, respectively. All rabbits were sacrificed with an intravenous injection of $100 \mathrm{mg} \mathrm{kg}^{-1}$ sodium pentobarbital. Cornea thickness was measured before and after injection, and before the cornea excision process via a pachymeter.

\subsubsection{Immunohistochemistry}

For histological investigation, corneas were fixed in 4\% paraformaldehyde and embedded in paraffin. Tissues were sectioned with a Leica microtome at $5 \mu \mathrm{m}$ thickness. Sections were deparaffinized in xylene and rehydrated in serial ethanol series for hematoxyline and eosin $(\mathrm{H} \& \mathrm{E})$ staining.

For immunohistochemistry experiments, sections were stained with anti-collagen I and anti-vimentin antibodies. Following deparaffinization and rehydration steps, antigen retrieval was performed using pepsin at $37^{\circ} \mathrm{C}$. Samples were treated with Tris-base saline (TBS) with $0.025 \%$ Triton X-100 twice for 5 min for permeabilization. Then, $10 \%$ normal serum with $1 \%$ BSA in TBS was added to samples, which were incubated for $2 \mathrm{~h}$ at RT in a humidified chamber. Primary antibodies for collagen I and vimentin were diluted in TBS with $1 \%$ BSA at ratios of 1:600 and 1:200, respectively. Samples were incubated with primary antibody overnight at $4{ }^{\circ} \mathrm{C}$. After incubation, samples were washed twice with $0.025 \%$ Triton $\mathrm{X}-100$ in TBS for $5 \mathrm{~min}$. Alexafluor 488 conjugated goat anti-mouse IgG (1:600) or Cy2 conjugated goat anti-mouse IgG (1:300) were used as secondary antibodies. After $1 \mathrm{~h}$ of incubation at RT, all samples were mounted onto glass slides using Prolong anti-fade mounting media.

\subsection{Statistical analyses}

Statistical analyses were performed using GraphPad Prism 5. To determine the statistical difference for both viability and proliferation assays, one-way ANOVA and Bonferroni's multiple comparison post-tests were employed. Error bars indicate standard error of mean.

\section{Results and discussion}

\subsection{Synthesis of PA molecules}

Two different bioactive PA molecules were designed and synthesized and used in in vitro and in vivo experiments (Fig. 1a and b). YIGSR-PA molecule, which is inspired from laminin, was designed to enhance cell adhesion and proliferation. Boateng et al. [23] previously demonstrated that YIGSR affects cell adhesion on neonatal myocytes and provides resistance to mechanical strain in cultured cells. In another study, YIGSR epitope was observed to promote adhesion and proliferation of human skin fibroblasts [29]. Fibronectin, which is an ECM glycoprotein, is involved in cell attachment like laminin. Since RGD, which is found in the fibronectin sequence, was reported to be important for recognition by integrins [30], KKRGD-PA was used to mimic the cell adhesive function of fibronectin. K-PA was used as a control nanofiber matrix without YIGSR or RGD epitopes, to test the bioactivity of the PA, and collagen was used as a positive control.

Three-dimensional networks composed of peptide nanofibers were obtained through inducing self-assembly via mixing two oppositely charged PA molecules. The PA molecules self-assemble via electrostatic interactions and hydrophobic collapse at physiological $\mathrm{pH}$, and encapsulation of water in 3-D networks of nanofibers results in gelation [18]. E-PA is a non-bioactive and negatively charged molecule (Fig. 1d), which was used for neutralization of positively charged YIGSR-PA, KKRGD-PA and K-PA molecules.

In vitro studies were carried out with positively charged PA molecules gelled with negatively charged E-PA addition. For analysis of the nanofibers that were formed in in vivo studies, nanofibers were formed by mixing CS with YIGSR-PA and KKRGD-PA, since the adult human corneal stroma, similar to rabbit, contains $65 \mathrm{wt} . \%$ keratan sulfate and $30 \mathrm{wt} . \%$ chondroitin/ dermatan sulfate (CS/DS) [31]. Because these glycosaminoglycans are highly negatively charged molecules, positively charged PA molecules formed gels upon injection into cornea.

\subsection{Characterization of self-assembled PA nanofibers}

Circular dichroism spectroscopy was used to characterize the formation of peptide nanostructures. The $\beta$-sheet secondary structure was found to be prevalent for all samples, which also indicates nanofiber formation driven by $\beta$-sheet structure (Fig. 2) [32]. CD spectra of PA-CS nanofibers are shown in Fig. S9. Nanofibers that were formed by $\beta$-sheet driven self-assembly of PA molecules were visualized by TEM and AFM imaging. TEM images of nanofibers formed with E-PA or CS are shown in Fig. 3b and Fig. S10b and e, respectively. These images reveal that all the PA combinations that were used for in vitro and in vivo experiments formed uniform nanofibers with diameters of $\sim 20-30 \mathrm{~nm}$. The fiber diameters were similar for all PA combinations. The bundles formed by PA nanofibers were analyzed by AFM (Fig. 3c, f, I and Fig. S10c, f). AFM images revealed that the nanofibers formed by all PA combinations used showed similar heights and morphologies.

The natural ECM is composed of a fibrous network and other structural and functional components that interact with cells. The organization of fibrils and lamellae affects the tensile strength of cornea and its transparency significantly [33]. Thus, when developing synthetic extracellular matrices, mimicking this fibrous network structure is an important task. PA molecules were previously shown to form nanofibrous networks similar to natural ECM. SEM imaging was used to investigate the general morphology of the hydrogels formed by the PA nanofibers. Critical-point drying was used to preserve the structure of the gels. The SEM images of YIGSR-PA/E-PA, KKRGD-PA/E-PA, K-PA/E-PA and of YIGSR-PA/CS and KKRGD-PA/CS nanofiber networks are shown in Fig. 3a, d and $g$ and Fig. S10a and d.

\subsection{In vitro characterization of cellular responses on PA nanofibers}

The HTK cell line was developed and investigated by Jester et al. [30]. Karyotype, morphological and physiological analyses showed that these immortalized cells have similar properties to primary corneal keratocytes [29]. HTK cells were used in order to investigate the effects of bioactive peptide nanofibers on keratocyte viability and proliferation in vitro. Cell viability was determined by Alamar blue assay after culturing cells on the nanofibers for $24 \mathrm{~h}$. Viability results indicated no significant difference among laminin-mimetic YIGSR-PA/E-PA, fibronectin mimetic KKRGD-PA/ E-PA and non-bioactive K-PA/E-PA nanofiber scaffolds (Fig. S11), suggesting that the bioactive sequences did not cause enhanced viability of corneal fibroblasts. HTK cells cultured on collagen showed higher viability than all PA groups. This might have been caused by the fact that collagen, as a natural component of ECM combines a comprehensive array of biological and mechanical signals supporting the viability of these cells. In order to analyze the effects of the bioactive PA on proliferation of HTK cells, the cells were analyzed by Alamar blue assay after $72 \mathrm{~h}$ of incubation. While HTK cells cultured on laminin mimetic YIGSR-PA/E-PA nanofibers 


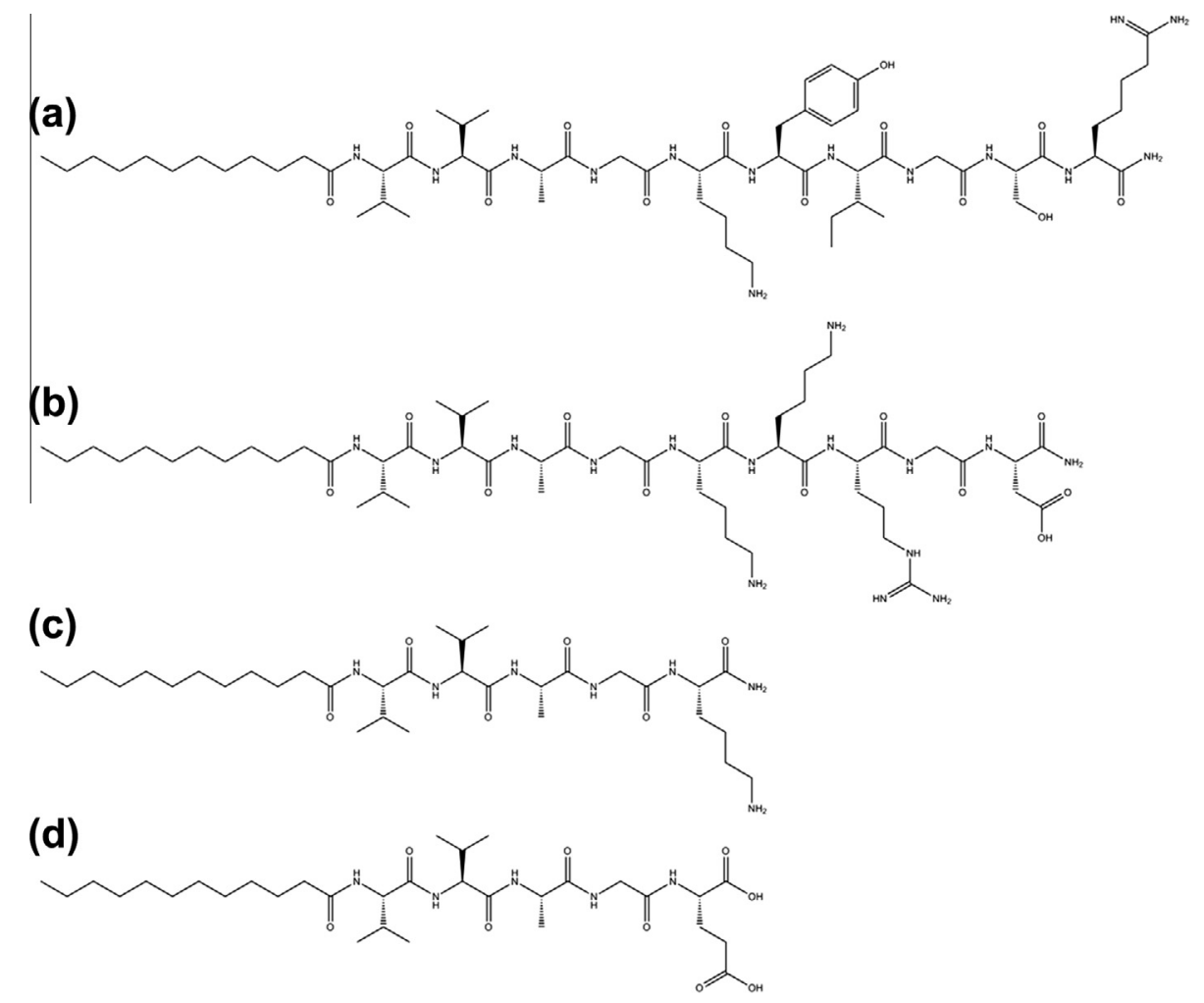

Fig. 1. Chemical structures of PA molecules: (a) YIGSR-PA; (b) KKRGD-PA; (c) K-PA; (d) E-PA.

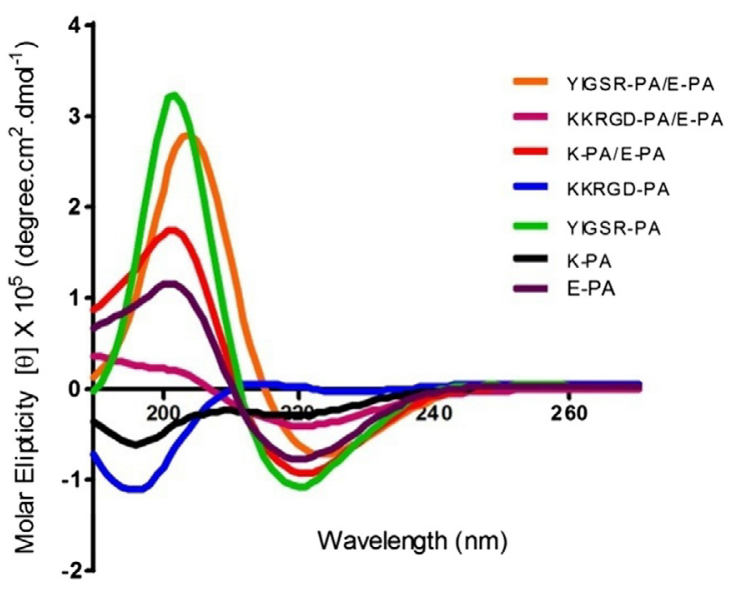

Fig. 2. Circular dichroism spectra of the peptide nanostructures. The PA molecules showed characteristic $\beta$-sheet structure at physiological $\mathrm{pH}$.

showed enhanced proliferation compared with cells cultured on K-PA/E-PA nanofibers, it was similar to that of cells on collagen coated wells (Fig. 4b). However, HTK cells cultured on fibronectin mimetic KKRGD-PA/E-PA nanofibers exhibited a slower proliferation rate than cells cultured on control nanofibers.

In their natural milieu, keratocytes need to adhere to the ECM in order to direct their cellular processes such as survival, migration or proliferation. When adhesion of cells on laminin mimetic YIGSR-PA/E-PA or fibronectin mimetic KKRGD-PA/E-PA nanofibers was investigated through SEM imaging, HTK cells grown on laminin mimetic nanofibers exhibited adhesion and spreading profile similar to cells cultured on collagen (Fig. 5a, d). However, the adhesion and spreading profiles of cells cultured on fibronectin mimetic nanofibers were similar to cells cultured on non-bioactive
K-PA/E-PA nanofibers (Fig. 5b, c). Immunohistochemical staining for vimentin, which is a major structural protein of keratocytes, also revealed a morphological profile of cells grown on different scaffolds similar to those observed in the SEM analysis (Fig. 6).

\subsection{Histological examination and analysis of rabbit corneas}

The effects of laminin mimetic and fibronectin mimetic PA gels on in vivo regeneration of corneal stroma were investigated using a rabbit corneal stromal pocket model. Corneal stromal pockets were surgically created as described in the methods section and filled with either YIGSR-PA or KKRGD-PA (Fig. 7), or left empty as negative controls. A pachymeter was employed to measure the central corneal thickness of the rabbit corneas $(n=5)$, and changes in the cornea thickness were investigated before and after injection. Since the stromal thickness profile provides information about changes in corneal regeneration [34], measurements were performed at 3 (Fig. S12a) or 7 (Fig. S12b) weeks after surgery before sacrificing the animals. After injection, there was an average increase of $100 \mu \mathrm{m}$ and $200 \mu \mathrm{m}$ in corneal thickness, for YIGSR-PA and KKRGD-PA treated animals, respectively. However, after 3 weeks, the increase in corneal thickness of PA injected samples disappeared, and no significant difference was observed among PA injected groups, the native group and the corneal pocket without injection group. Measurements at 7 weeks also revealed a similar profile.

In order to investigate the regeneration process in PA gel injected and control cornea samples, histological and immunohistochemical analyses were carried out. H\&E staining was performed to observe the morphology of damaged and newly formed ECM and cell migration after surgery (Fig. 8). H\&E staining revealed that laminin mimetic YIGSR-PA (Fig. 8a) induced keratocyte migration and stromal regeneration in the stromal dissection site without any changes in the corneal morphology compared with native 

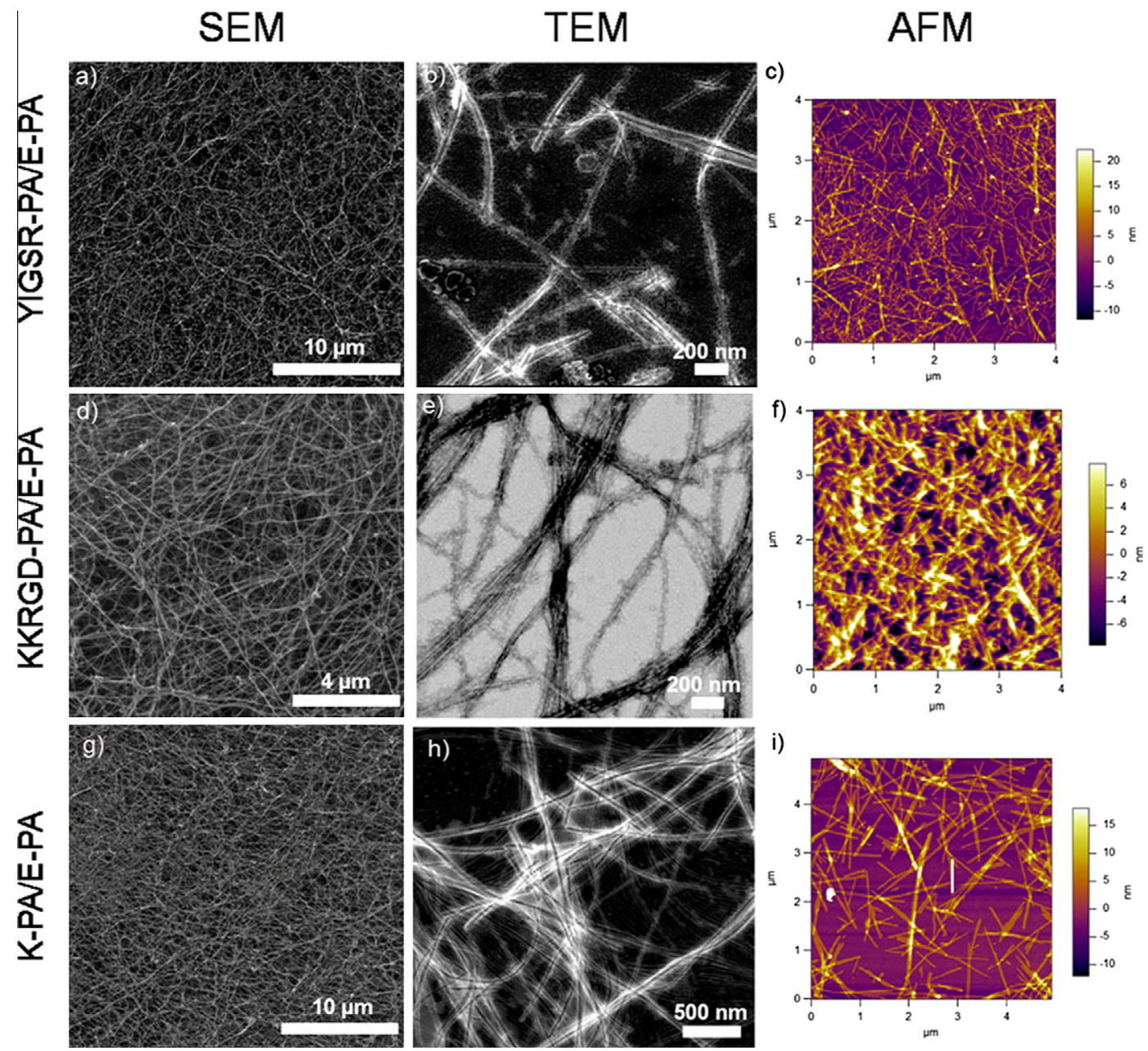

Fig. 3. SEM, TEM and AFM images of (a-c) YIGSR-PA gel formed with E-PA, (d-f) KKRGD-PA gel formed with E-PA and (g-i) K-PA gel formed with E-PA.

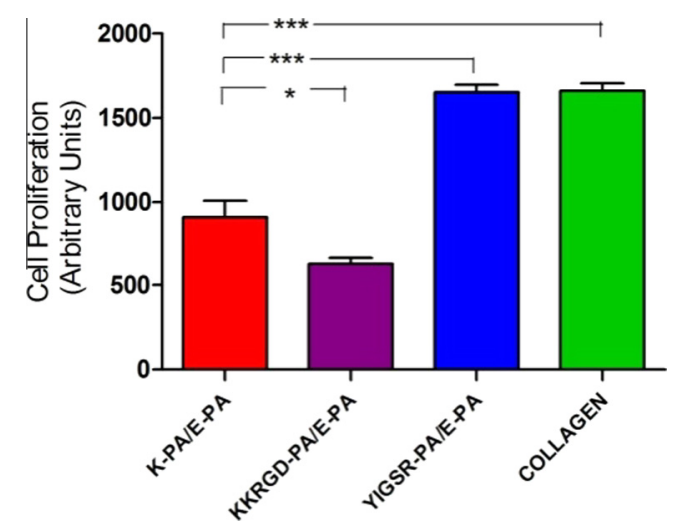

Fig. 4. Proliferation results of corneal fibroblasts at $72 \mathrm{~h}$. The YIGSR-PA nanofibers exhibited a similar proliferation profile on the HTK cell line compared with collagen.

cornea (Fig. S13). The corneal morphology was not preserved in the case of fibronectin-mimetic KKRGD-PA injection when inspected 3 weeks after surgery (Fig. 8e). In addition, there was no cell migration to the stromal dissection site in KKRGD-PA injected samples, which was similar to corneal pocket without injection samples, where no PA was injected (Fig. 8i). These results show that laminin-mimetic YIGSR-PA was the driving factor for inducing cellular migration to the stromal dissection site after surgery.
The morphology and protein content of the stromal ECM were further investigated by anti-collagen I and anti-vimentin immunostaining. Collagen forms $\sim 80 \%$ of the organic content of the corneal stroma, and type I collagen is the most abundant collagenous component contributing to corneal transparency through the well-organized collagen I fibrils [35]. In order to regenerate damaged stroma, collagen I synthesis and lamellar organization of the fibrils is necessary. Thus, anti-collagen I staining was performed to observe its synthesis and organization. Three weeks after surgery, collagen I expression was observed in all groups. However, although lamellar organization of collagen I in the corneal dissection area was similar in YIGSR-PA, non-dissected control group and corneal pocket without injection group, the KKRGD-PA injected samples exhibited a wavy organizational pattern, which shows that the type of bioactive epitope is an important determinant of the regeneration inducing capability of hydrogels formed by PA molecules.

Anti-vimentin staining was performed to visualize the cells that migrated to the corneal dissection site. Vimentin is an intermediate filament protein and a well-known keratocyte marker. An increased amount of cells migrated to the corneal dissection site in the presence of YIGSR-PA injection in all four animals tested, and these cells were positive for anti-vimentin staining. However, no cell migration to the damaged area was observed in KKRGD-PA injected animals $(n=3)$ and the corneal pocket without injection group $(n=3)$ (Fig. $8 \mathrm{~g}, \mathrm{k}$ ).

After corneal dissection, while some keratocytes undergo apoptosis, others secrete ECM, which fills the gap in the damaged 

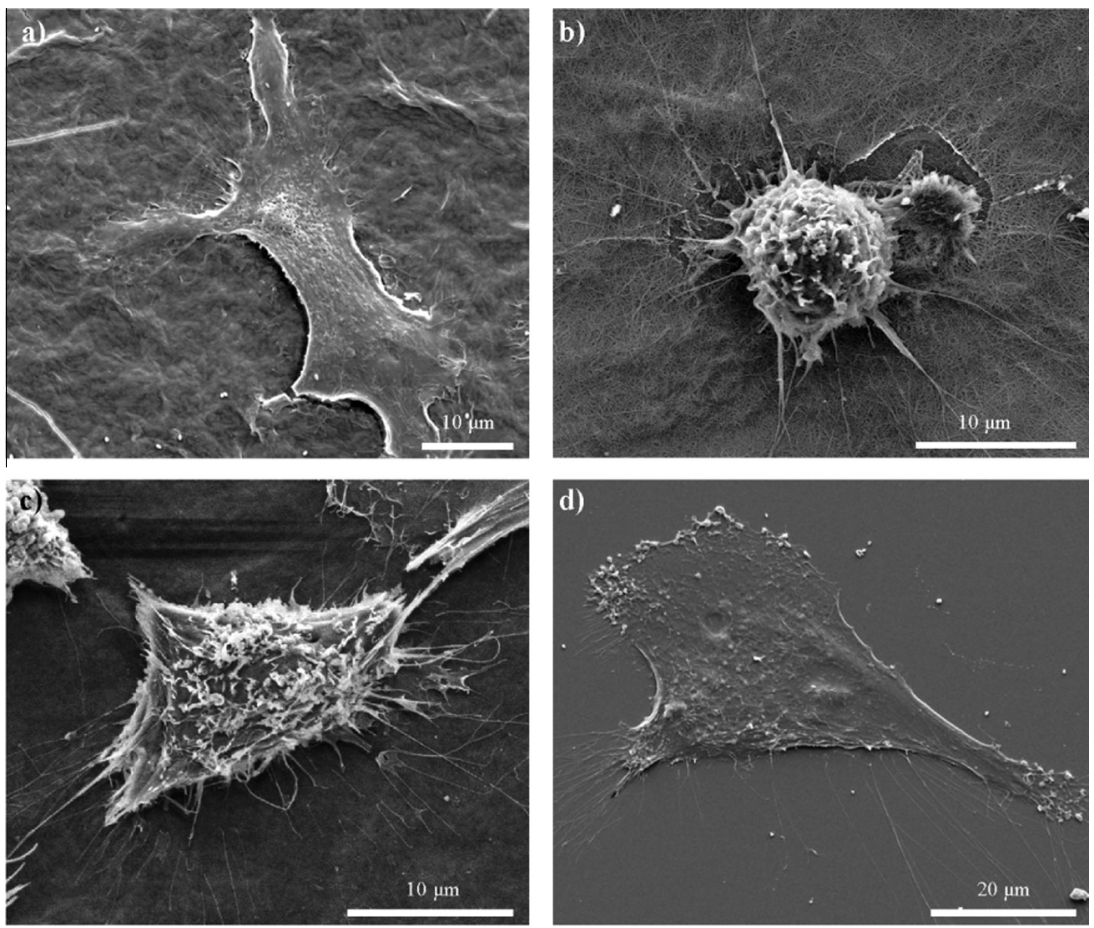

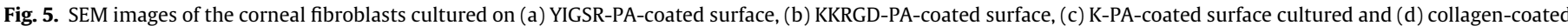
surface showing the adhesion profiles of cells.
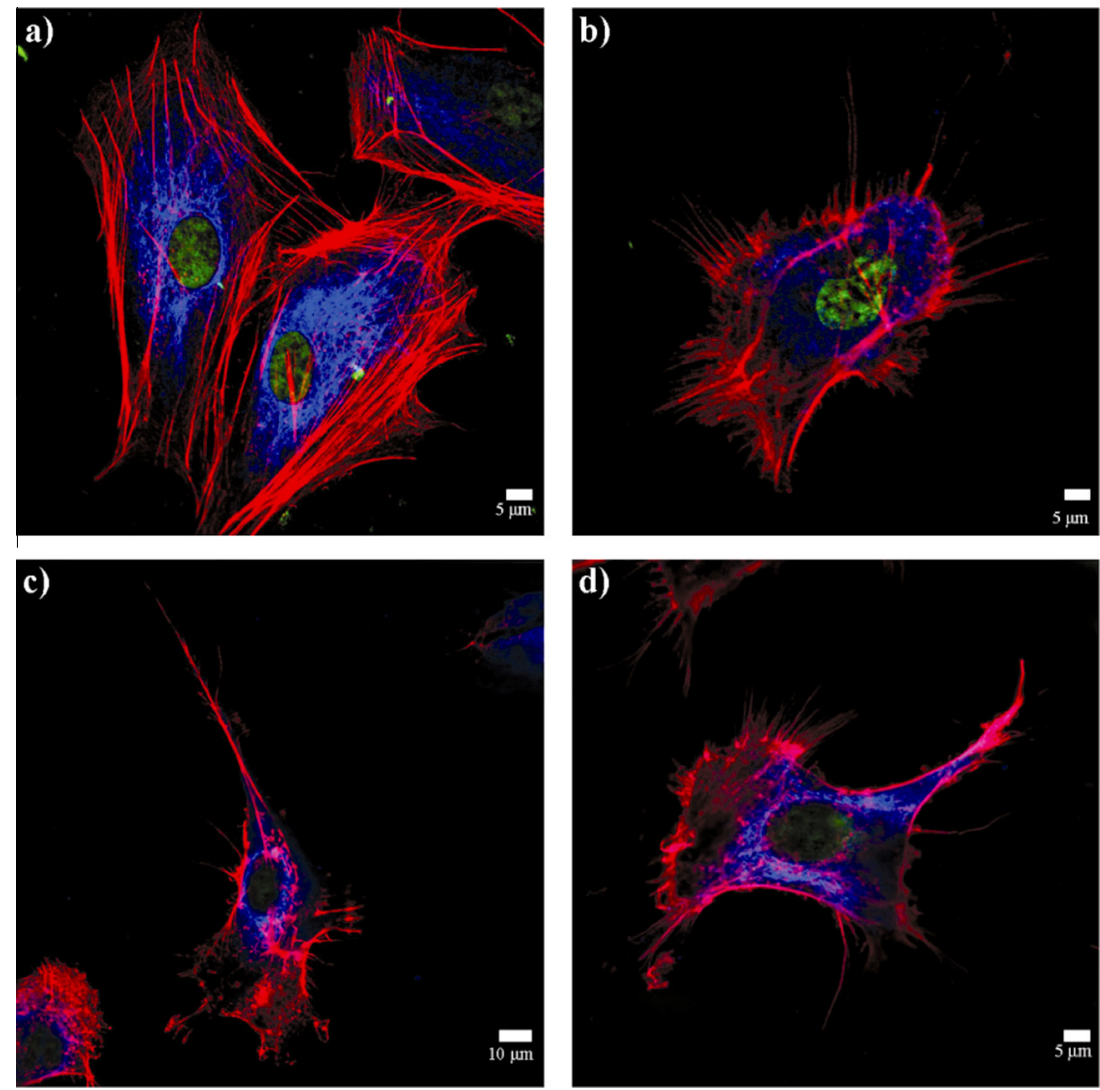

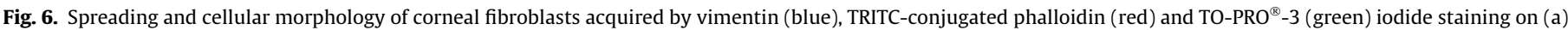
YIGSR-PA-coated surface, (b) KKRGD-PA-coated surface, (c) K-PA-coated surface cultured and (d) collagen-coated surface.

area [32]. Injection of YIGSR-PA gel to the corneal stromal pocket induced keratocyte migration and collagen I expression, enhancing stroma regeneration 3 weeks after surgery. In the corneal pocket without injection group, even though there was collagen I 

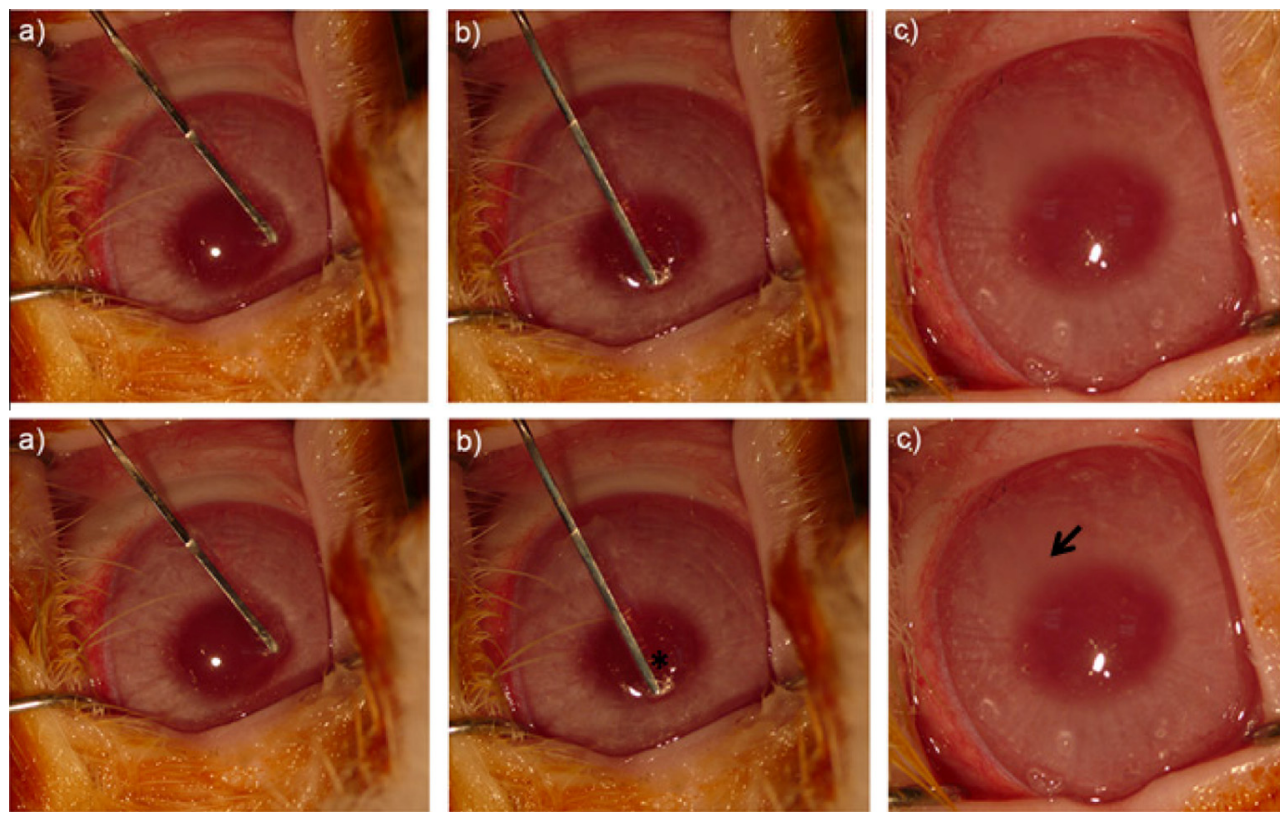

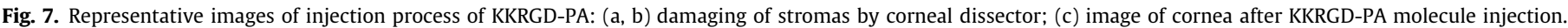
Asterisk indicates damaged area of corneal stroma, and arrow indicates the PA gels.
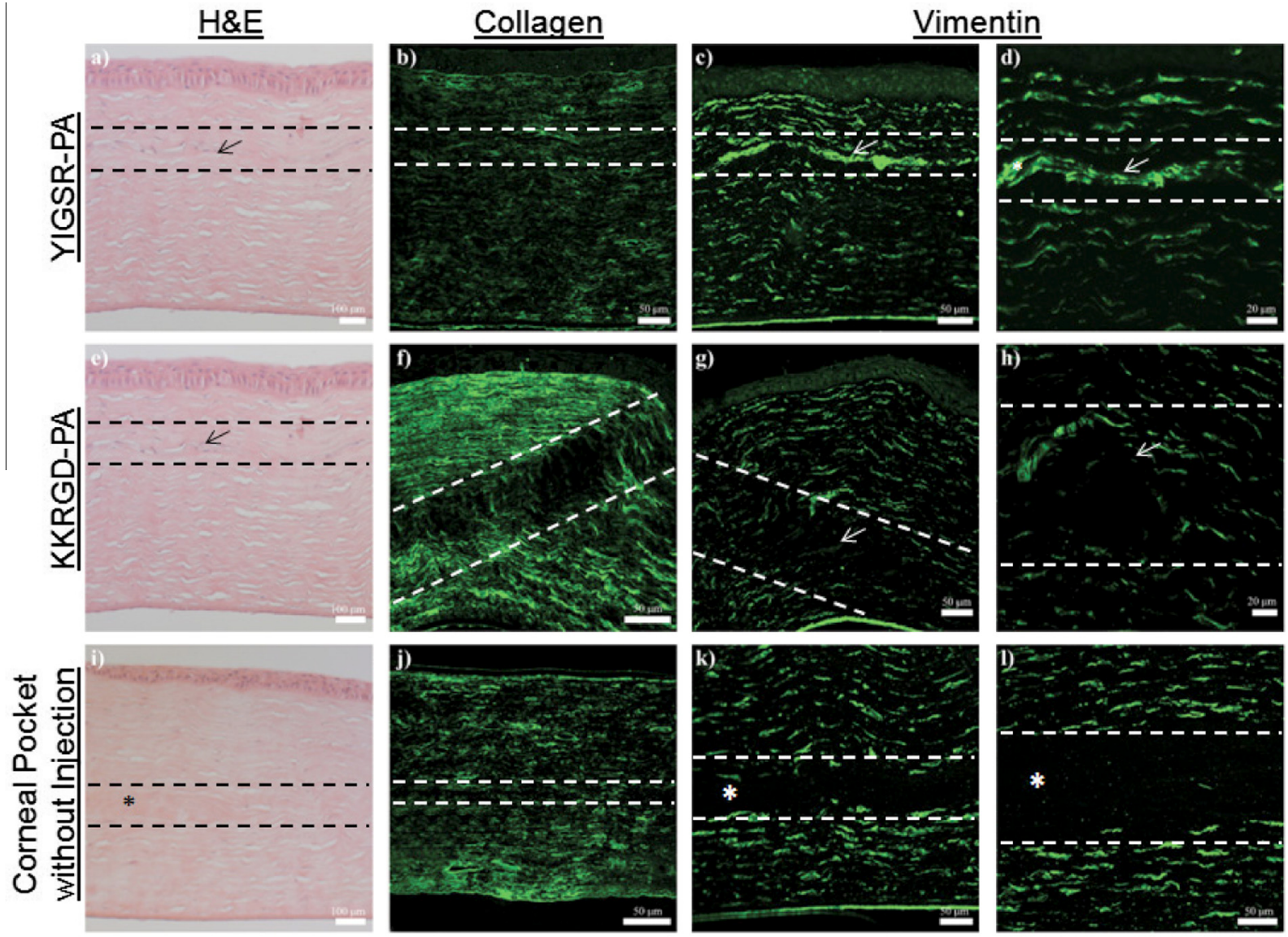

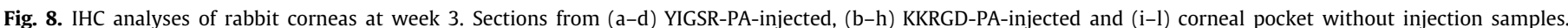
Asterisks indicate dissection area of corneal stroma, and arrows indicate the PA gels. Scale bars: (a), (e) and (i) $100 \mu \mathrm{m}$; (b), (c), (d), (f), (g), (h), (j), (k) and (l) $50 \mu \mathrm{m}$.

synthesis, keratocytes were not observed inside the newly formed tissue. A similar pattern was also observed for KKRGD-PA injected corneas. Lack of cell migration into the peptide nanofiber gels in
KKRGD-PA group suggests that the type of bioactive epitope that is presented on the PA nanofibers is important for achieving keratocyte migration. 
Late stromal regeneration was investigated by histological and IHC staining at 7 weeks after surgery. In YIGSR-PA injected samples, H\&E staining as well as anti-collagen I and anti-vimentin staining exhibited a similar profile to that observed at week 3, where keratocyte migration and collagen I synthesis was induced (Fig. 9a, b). The cell migration profile and collagen I organization of the corneal pocket without injection group were also similar to those observed at 3 weeks (Fig. 9e, f). However, KKRGD-PA injected samples showed a different profile at week 7 compared with week 3, where collagenous lamellae were more organized and similar to healthy cornea, although there was still no keratocyte migration (Fig. 9i, j).

Comparison between anti-collagen I and anti-vimentin staining of KKRGD-PA injected and corneal pocket without injection groups revealed a similar healing process and no cell migration at week 7 (Fig. 9e-1), which further supports the importance of the type of bioactivity that is displayed on the peptide nanofibers on their regeneration induction capability. Although the fibronectinderived RGD sequence is a widely used bioactive, cell-adhesive peptide, the presentation of this sequence on PA nanofibers did not induce cellular migration of keratocytes into the injection site in the corneal regeneration model. The laminin-derived YIGSR sequence is another widely used cell adhesive peptide and was previously shown to enhance corneal regeneration when used together with a collagen-containing copolymer [36]. When this sequence was displayed on peptide nanofiber scaffolds, stromal regeneration and keratocyte migration were enhanced in the present study as well. Although RGD functionalized artificial scaffolds were previously shown to support corneal fibroblast activity [37], the RGD functionalized peptide nanofiber system did not induce similar activity in the present study, which suggests that the scaffold material itself also might affect the bioactivity of the signal sequences. Overall, the ease of injection of the PA solutions into the corneal pocket, as well as versatility of the peptide sequences that can be used in their design makes PA molecules attractive materials for corneal tissue regeneration.

Studies on the regeneration of cornea have generally focused on two approaches: one is in vitro production of cornea in culture, and the other is in vivo regeneration of the cornea via use of tissue engineered matrixes. In the first approach, keratocytes and/or fibroblasts are directed to produce corneal ECM components in cell culture media. Gaudreault et al. [38] stimulated dermal fibroblasts by ascorbic acid to produce ECM and collagen. ECM layers were stacked together one above the other and further processed in cell culture to form the corneal stroma. The primary problem in this technique is that the time period to produce transplantable cornea was too long [38]. Carrier et al. [39] used a combination of human dermal fibroblasts and keratocytes in corneal stroma production to promote rapid and healthy epithelial healing. This approach enabled production of cultured corneal stroma with mechanical and microstructural properties similar to native human cornea [39]. Guo et al. [40] cultured human keratocytes and stimulated them to produce corneal ECM. Within 4 weeks, they produced $36-\mu \mathrm{m}$ thick stroma similar to human corneal stroma [40]. Vrana et al. [41] inserted keratocytes into the porous matrix containing collagen and CS to produce corneal stroma, after which they implanted epithelial and endothelial layers. With this approach, they were able to produce all three layers of the cornea [41].

The second approach, which is in vivo regeneration of the cornea via use of tissue engineered matrices, uses ECM properties that direct cell proliferation and differentiation. Type 1 collagen matrix was the most commonly researched macromolecule for in vivo
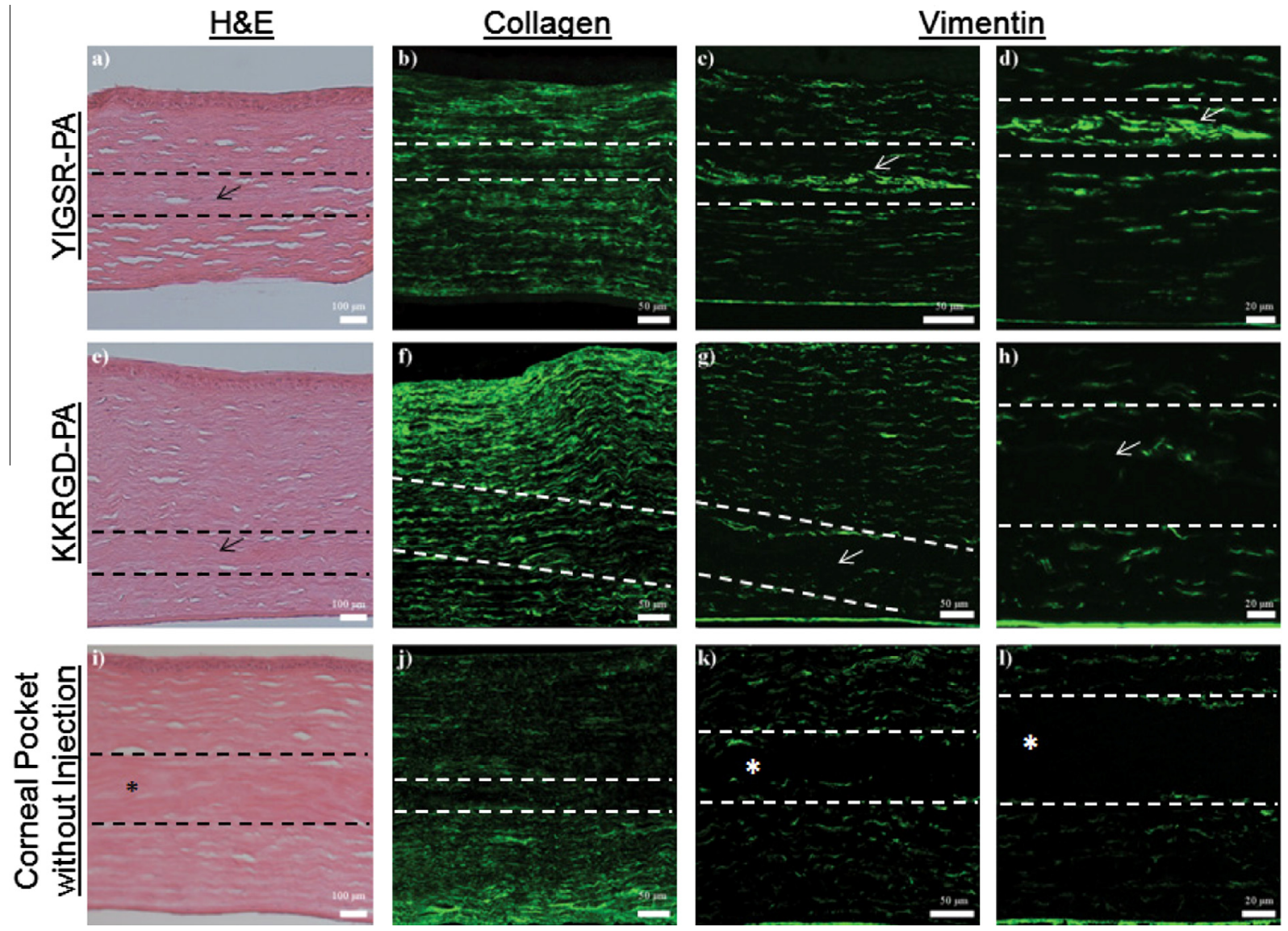

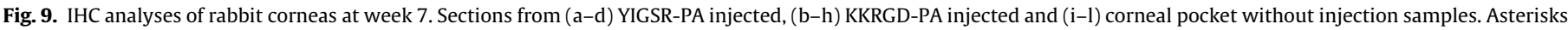
indicate dissection area of corneal stroma, and arrows indicate the PA gels. Scale bars: (a), (e) and (i) $100 \mu \mathrm{m}$; (b), (c), (d), (f), (g), (h), (j), (k) and (l) $50 \mu \mathrm{m}$. 
corneal regeneration. In cell culture, keratocytes could convert collagen type 1 matrix into lamellar stroma similar to human corneal stroma $[42,43]$. Recombinant human collagen type 1 and 3 (RHC1 and RHC3) containing ECM mimetics were implanted into animal corneas using lamellar keratoplasty techniques [44]. After 12 months' follow-up, both RHC1 and RHC3 integrated into the animals' corneas, and the corneas sustained their optical clarity. Light microscopy and TEM revealed that corneal lamellar structure was formed similar to native cornea. Upon these findings, human study was started for 10 patients with keratoconus and stromal scarring were included in the study. Parallel to the animal studies, RHC integrated into the human corneas and corneas sustained their optical clarity. Keratocytes settled into the collagen matrix and converted it into lamellar corneal stroma [45]. In the present work, YIGSR peptide nanofiber scaffold promoted keratocyte migration into the scaffold, and the keratocytes converted the peptide nanofiber matrix into the lamellar corneal stroma. Preservation of the optical clarity of the animal corneas together with histological findings shows that peptide YIGSR-PA nanofiber scaffolds can achieve corneal stroma regeneration without any significant injury to the cornea.

In clinical practice, injectable peptide nanofiber scaffolds have several promising advantages over other corneal stromal regeneration approaches. Injectable matrices may give flexibility of applications in corneal tissues. They could be used to fill and regenerate a defect area of the cornea, especially in corneal diseases with stromal thinning, such as keratoconus and pellucid marginal degeneration. Addition of extra stromal tissue to the peripheral cornea may also reverse myopic refractive errors; conversely, addition to central cornea could reverse hypermetropic refractive errors.

\section{Conclusion}

This study investigated the potential of peptide nanofiber scaffolds decorated with bioactive laminin derived YIGSR and fibronectin RGD peptides for corneal regeneration. To the best of the present authors' knowledge, this is the first time that peptide nanofiber scaffolds have been used for corneal stroma regeneration. Chemical and physiological characterization studies indicated that all groups exhibited ECM mimicking nanofibrous morphology with $\beta$-sheet secondary structure, which was driven through selfassembly of PA molecules. In vitro studies showed that PA nanofibers were biocompatible with the human stromal keratocyte cell line, HTK cells, and supported their adhesion and viability. In in vitro cell proliferation assays, laminin-mimetic YIGSR-PA nanofibers showed an enhanced effect on cell proliferation compared with other PA groups. The in vivo cornea damage model demonstrated that the YIGSR-PA injection to the damage site induced keratocyte migration and collagen I synthesis, which is an indication of corneal stroma regeneration. However, when presented on PA nanofibers, the fibronectin-derived RGD sequence, which is widely used for enhancing cell adhesion for various purposes, did not show a similar effect to YIGSR-PA. Although collagen I synthesis in the damage site was detected in the fibronectin mimetic peptide nanofiber injected samples and the corneal pocket without injection controls, there was a striking absence of cells in the damage area, which shows the importance of the type of bioactive epitope for specific applications. In conclusion, the laminin mimetic YIGSR functionalized peptide nanofiber system presents a promising scaffold for corneal stroma regeneration.

\section{Acknowledgements}

The authors thank M. Guler, Z. Erdoğan and T. Ozcan for helping with TEM, LC-MS and tissue blocking experiments. This work was supported by the Scientific and Technological Research Council of Turkey (TUBITAK) Grant numbers 110S454, 111M410, 111M710 and COMSTECH-TWAS Grant. M.O.G and A.B.T. acknowledge support from the Turkish Academy of Sciences Distinguished Young Scientist Award (TUBA-GEBIP).

\section{Appendix A. Figures with essential colour discrimination}

Certain figures in this article, particularly Figs. 2-4 and 6-9 are difficult to interpret in black and white. The full colour images can be found in the on-line version, at http://dx.doi.org/10.1016/ j.actbio.2013.12.002.

\section{Appendix B. Supplementary data}

Supplementary data associated with this article can be found, in the online version, at http://dx.doi.org/10.1016/j.actbio.2013.12. 002.

\section{References}

[1] Griffith M, Osborne R, Munger R, Xiong X, Doillon CJ, Laycock NL, et al. Functional human corneal equivalents constructed from cell lines. Science 1999;286(5447):2169-72.

[2] Morishige N, Petroll WM, Nishida T, Kenney MC, Jester JV. Noninvasive corneal stromal collagen imaging using two-photon-generated second-harmonic signals. J Cataract Refract Surg 2006;32(11):1784-91.

[3] Torbet J, Malbouyres M, Builles N, Justin V, Roulet M, Damour O, et al. Orthogonal scaffold of magnetically aligned collagen lamellae for corneal stroma reconstruction. Biomaterials 2007;28(29):4268-76.

[4] Whitcher JP, Srinivasan M, Upadhyay MP. Corneal blindness: a global perspective. Bull World Health Organ. 2001;79(3):214-21.

[5] Whitcher JP, Srinivasan M, Upadhyay MP. Prevention of corneal ulceration in the developing world. Int Ophthalmol Clin. 2002;42(1):71-7.

[6] Hay ED, Meier S. Stimulation of corneal differentiation by interaction between cell surface and extracellular matrix. II. Further studies on the nature and site of transfilter "induction". Dev Biol 1976:52(1):141-57.

[7] Hicks CR, Fitton JH, Chirila TV, Crawford GJ, Constable IJ. Keratoprostheses: advancing toward a true artificial cornea. Surv ophthalmol 1997;42(2): $175-89$.

[8] Germain L, Carrier P, Auger FA, Salesse C, Guérin SL. Can we produce a human corneal equivalent by tissue engineering? Progr Retinal Eye Res 2000;19(5): 497-527.

[9] Bleckmann H, Holak S. Preliminary results after implantation of four AlphaCor artificial corneas. Graefes Arch Clin Exp Ophthalmol 2006;244(4):502-6.

[10] Hicks CR, Crawford GJ, Lou X, Tan DT, Snibson GR, Sutton G, et al. Corneal replacement using a synthetic hydrogel cornea, AlphaCor: device, preliminary outcomes and complications. Eye (Lond) 2003:17(3):385-92.

[11] Chow CC, Kulkarni AD, Albert DM, Darlington JK, Hardten DR. Clinicopathologic correlation of explanted AlphaCor artificial cornea after exposure of implant. Cornea 2007;26(8):1004-7.

[12] Liu W, Merrett K, Griffith M, Fagerholm P, Dravida S, Heyne B, et al. Recombinant human collagen for tissue engineered corneal substitutes. Biomaterials 2008;29(9):1147-58.

[13] Orwin EJ, Hubel A. In vitro culture characteristics of corneal epithelial, endothelial, and keratocyte cells in a native collagen matrix. Tissue Eng 2000;6(4):307-19.

[14] Alaminos M, Del Carmen Sanchez-Quevedo M, Munoz-Avila JI, Serrano D, Medialdea S, Carreras I, et al. Construction of a complete rabbit cornea substitute using a fibrin-agarose scaffold. Invest Ophthalmol Vis Sci 2006;47(8):3311-7.

[15] Hashimoto Y, Funamoto S, Sasaki S, Honda T, Hattori S, Nam K, et al. Preparation and characterization of decellularized cornea using highhydrostatic pressurization for corneal tissue engineering. Biomaterials 2010:31(14):3941-8.

[16] Carlsson DJ, Li F, Shimmura S, Griffith M. Bioengineered corneas: how close are we? Curr Opin Ophthalmol 2003;14(4):192-7.

[17] Toksöz S, Guler MO. Self-assembled peptidic nanostructures. Nano Today 2009;4(6):458-69.

[18] Niece KL, Hartgerink JD, Donners JJ, Stupp SI. Self-assembly combining two bioactive peptide-amphiphile molecules into nanofibers by electrostatic attraction. J Am Chem Soc 2003;125(24):7146-7.

[19] Shah RN, Shah NA, Del Rosario Lim MM, Hsieh C, Nuber G, Stupp SI. Supramolecular design of self-assembling nanofibers for cartilage regeneration. Proc Natl Acad Sci USA 2010;107(8):3293-8.

[20] Mata A, Geng Y, Henrikson KJ, Aparicio C, Stock SR, Satcher RL, et al. Bone regeneration mediated by biomimetic mineralization of a nanofiber matrix. Biomaterials 2010;31(23):6004-12. 
1166

G. Uzunalli et al./Acta Biomaterialia 10 (2014) 1156-1166

[21] Silva GA, Czeisler C, Niece KL, Beniash E, Harrington DA, Kessler JA, et al. Selective differentiation of neural progenitor cells by high-epitope density nanofibers. Science 2004;303(5662):1352-5.

[22] Chow LW, Bitten R, Weber MJ, Carvajal D, Shul KR, Sharma AK, et al. A bioactive self-assembled membrane to promote angiogenesis. Biomaterials 2011;32(6):1574-82.

[23] Boateng SY, Lateef SS, Mosley W, Hartman TJ, Henley L, Russell B. RGD and YIGSR synthetic peptides facilitate cellular adhesion identical to that of laminin and fibronectin but alter the physiology of neonatal cardiac myocytes. Am J Physio Cell Physiol 2005;288(1):C30-8.

[24] Cassia SP, Roo SS, Hubbell JA. Covalently immobilized laminin peptide Tyr-IleGly-Ser-Arg (YIGSR) supports cell spreading and co-localization of the 67kilodalton laminin receptor with alpha-actinin and vinculin. J Biol Chem 1993;268(11):8053-9.

[25] Fittkau MH, Zilla P, Bezuidenhout D, Lutolf MP, Human P, Hubbell JA, et al. The selective modulation of endothelial cell mobility on RGD peptide containing surfaces by YIGSR peptides. Biomaterials 2005;26(2):167-74.

[26] Saiki I, Murata J, Iida J, Sakurai T, Nishi N, Matsuno K, et al. Antimetastatic effects of synthetic polypeptides containing repeated structures of the cell adhesive Arg-Gly-Asp (RGD) and Tyr-Ile-Gly-Ser-Arg (YIGSR) sequences. Br J Cancer 1989;60(5):722.

[27] Walker JR, Altman E, Roth JR. An in vino study of novel bioactive peptides that inhibit the growth of Escherichia coli. J Peptide Res 2001;58(5):380-8.

[28] Marletta G, Ciapetti G, Satriano C, Pagani S, Baldini N. The effect of irradiation modification and RGD sequence adsorption on the response of human osteoblasts to polycaprolactone. Biomaterials 2005;26(23):4793-804.

[29] Klenkler B, Sheardown H. Growth factors in the anterior segment: role in tissue maintenance, wound healing and ocular pathology. Exp Eye Res 2004; 79(5):677-88.

[30] Jester JV, Huang J, Fisher S, Spiekerman J, Chang JH, Wright WE, et al. Myofibroblast differentiation of normal human keratocytes and hTERT extended-life human corneal fibroblasts. Invest Ophthalmol Vic Sci 2003;44(5):1850-8.

[31] Conrad AH, Zhang Y, Tasheva ES, Conrad GW. Proteomic analysis of potential keratin sulfate, chondroitin sulfate A, and hyaluronic acid molecular interactions. Invest Ophthalmol Vic Sci 2010;51(9):4500-15.

[32] Morgan AW, Roskov KE, Lin-Gibson S, Kaplan DL, Becker ML, Simon Jr CG. Characterization and optimization of RGD-containing silk blends to support osteoplastic differentiation. Biomaterials 2008;29(16):2556-63.

[33] Etherege L, Kane BP, tassel JR. The effect of growth factor signaling on keratocytes in vitro and its relationship to the phases of stromal wound repair. Invest Ophthalmol Vis Sci 2009;50(7):3128-36.
[34] Reinstein DZ, Archer TJ, Gobbe M, Silverman RH, Coleman DJ. Stromal thickness in the normal cornea: three-dimensional display with Artemis very high-frequency digital ultrasound. J Refract Surg (Thorofare, NJ: 1995). 2009;25(9):776.

[35] Ishizaki M, Zhu G, Haseba T, Chafer S, Ko W. Expression of collagen I, smooth muscle alpha-actin, and vimentin during the healing of alkali-burned and lacerated corneas. Invest Ophthalmol Visual Sci 1993;34(12):3320-8.

[36] Li F, Carlson D, Lehmann C, Suuronen E, Vascotto S, Kobuch K, et al. Cellular and nerve regeneration within a biosynthetic extracellular matrix for corneal transplantation. Proc Natl Aced Sci 2003;100(26):15346-51.

[37] Gil ES, Mandal BB, Park S-H, Merchant JK, Omenetto FG, Kaplan DL. Helicoidal multi-lamellar features of RGD-functionalized silk biomaterials for corneal tissue engineering. Biomaterials 2010;31(34):8953-63.

[38] Gaudreault M, Carrier P, Larouche K, Leclerc S, Giasson M, Germain L, et al. Influence of sp 1/sp3 expression on corneal epithelial cells proliferation and differentiation properties in reconstructed tissues. Invest Ophthalmol Visual Sci 2003;44(4):1447-57.

[39] Carrier P, Deschambeault A, Talbot M, Giasson CJ, Auger FA, Guérin SL, et al. Characterization of wound reepithelialization using a new human tissueengineered corneal wound healing model. Invest Ophthalmol Visual Sci 2008;49(4):1376-85.

[40] Gro X, Hutcheon AE, Melotti SA, Zieske JD, Trinkaus-Randall V, Ruberti JW. Morphologic characterization of organized extracellular matrix deposition by ascorbic acid-stimulated human corneal fibroblasts. Invest Ophthalmol Visual Sci 2007;48(9):4050-60.

[41] Vrana NE, Builles N, Justin V, Bednarz J, Pellegrini G, Ferrari B, et al. Development of a reconstructed cornea from collagen-chondroitin sulfate foams and human cell cultures. Invest Ophthalmol Visual Sci 2008;49(12):5325-31.

[42] Borene ML, Barocas VH, Huber A. Mechanical and cellular changes during compaction of a collagen-sponge-based corneal stromal equivalent. Ann Boomed Eng 2004;32(2):274-83.

[43] Crabs RA, Chat EP, Evans MC, Barocas VH, Huber A. Biomechanical and microstructural characteristics of a collagen film-based corneal stroma equivalent. Tissue Eng 2006;12(6):1565-75.

[44] Terret K, Fagerholm P, McLaughlin CR, Dravida S, Lagali N, Shinozaki N, et al. Tissue-engineered recombinant human collagen-based corneal substitutes for implantation: performance of type I versus type III collagen. Invest Ophthalmol Visual Sci 2008;49(9):3887-94.

[45] Fagerholm P, Lagali NS, Carlsson DJ, Merrett K, Griffith M. Corneal regeneration following implantation of a biomimetic tissue-engineered substitute. CTS-Clin Transl Sci 2009;2(2):162-4. 